\title{
A Review of Performance Evaluation Measures for Actively-Managed Portfolios
}

\author{
${ }^{*}$ Heng-Hsing Hsieh, Kathleen Hodnett \\ University of the Western Cape, South Africa \\ *ahsieh@uwc.ac.za
}

\begin{abstract}
In the recognition that investment management is an on-going process, the performance of actively-managed portfolios need to be monitored and evaluated to ensure that funds under management are efficiently invested in order to satisfy the mandate specified in the policy statement. This paper discusses the primary performance evaluation techniques used to measure a portfolio's basic risk and return characteristics, risk-adjusted performance, performance attribution and market timing ability. It is concluded that the Treynor measure is more suitable for evaluating portfolios that are constituents of a broader portfolio, while the information ratio is useful for evaluating hedge funds with an absolute return objective. Although the Sharpe ratio and M-squared arrive at the same evaluation result, M-squared provides a direct comparison between the portfolio and the benchmark. With regard to the analysis of portfolio performance attribution, it is found that the return-based multifactor model of Sharpe (1992) is not suitable for analyzing the performance of hedge funds that engage in short-selling, leverage and derivatives. Additional factors generated by factor analysis could be used as factors in the extended model of Sharpe (1992) to analyze hedge fund return attributions. Finally, the Treynor and Mazuy (1966) model and the Henriksson and Merton (1981) model essentially distinguish the market timing ability from the security selection ability of the portfolio manager.
\end{abstract}

Keywords: Performance evaluation measures, performance attribution, market timing, active portfolio management, passive portfolio management

\section{Introduction}

Investment management refers to the process of managing collective investment schemes with an objective to create wealth that is governed by the mandate specified in the policy statement. The investment management process is research-driven, and typically involves the application of quantitative techniques to solve complex problems in order to achieve desired investment management outcomes. There are two major branches in investment management: active portfolio management; and passive portfolio management. While passive portfolio management involves tracking the desired exposure in a pre-specified benchmark, active portfolio management has an objective of outperforming the benchmark portfolio of similar risk level and investment style. The primary concern for active portfolio managers is the ability of the portfolio to outperform the benchmark on a risk-adjusted basis. To improve the risk-adjusted performance of an actively-managed portfolio, factors that differentiate the performance between the portfolio and the benchmark must be identified. These factors include the asset allocation ability, the security selection ability and the market timing ability of the portfolio manager.

In the recognition that investment management is an on-going process, portfolio performance needs to be monitored and evaluated regularly. This paper aims to discuss the rationale behind the essential measures used to evaluate portfolio performance. The remainder of the paper demonstrates and compares the uses of performance evaluation measures based on the following categories: basic return and risk measures; the risk-adjusted performance measures and the performance attribution techniques. While the basic return and risk measures and the risk-adjusted performance measures aim at evaluating the overall performance of the actively-managed portfolio, the primary application of the performance attribution techniques is to dissect the performance of the portfolio in order to identify whether the primary source of performance is due to the asset allocation, security selection or market timing decision of the portfolio manager. 


\section{Basic Return and Risk Measures}

Measures of portfolio return: The simplest way to measure the ability of wealth creation of an investment is the computation of the investment's returns from time to time. The return of a portfolio $X$ in month $t$ is the weighted average monthly return of its constituents in month $t$ as shown in Equation 1:

$r_{X, t}=\sum_{i=1}^{n} w_{X, i, t} \times r_{i, t}$

Where:

$r_{X . t} \quad$ is the return of index $X$ in month $t$;

$n \quad$ is the number of constituents in portfolio $X$;

$w_{X, i, t} \quad$ is the weight of the $i$ th constituent in portfolio $X$ in month $t$; and

$r_{i, t} \quad$ is the return of the $i$ th constituent in portfolio $X$ in month $t$.

Once the monthly portfolio returns over the evaluation period from 1 to $T$ are computed, the arithmetic return of portfolio $X$ over $T$ months is computed using Equation 2:

$R_{X(\text { Arithmetic })}=\frac{\sum_{t=1}^{T} r_{X, t}}{T}$

Where:

$T \quad$ is the number of months in the evaluation period; and

$r_{X, t} \quad$ is the return of portfolio $X$ in month $t . t=1 \ldots T$.

Although arithmetic portfolio return is easy to compute, Damato (2001) demonstrates the ambiguity caused by the arithmetic average of historical gains and losses. Suppose the original capital of $\$ 100$ is invested over a two-month period with $10 \%$ return in the first month and $10 \%$ loss in the second month. The arithmetic average return of $0 \%$, calculated as $(10 \%-10 \%) / 2$, implies that there is no change in the $\$ 100$ invested. However, the actual gain/loss for the investment grows from $\$ 100$ to $\$ 110$ in the first month, and drops $10 \%$ from $\$ 110$ to $\$ 99$ in the second month, indicating an actual loss of $\$ 1$.

The geometric return that incorporates the compounding effect of growth is a better indication of historical performance. The geometric return for portfolio $X$ over $T$ months is calculated using Equation 3:

$R_{X}=\left[\prod_{t=1}^{T}\left(1+r_{X, t}\right)\right]^{1 / T}-1$

Using the example of $\$ 100$ initial investment above, the geometric return is calculated as [( $1+0.10) \times$ [ $1-$ $0.10)]^{1 / 2}-1=-0.5013 \%$, indicating a loss of $0.5013 \%$ per month.

DeFusco, McLeavey, Pinto and Runkle (2004) indicate that geometric return focuses on the profitability of multiple investment periods and is of interest in evaluating historical holding period performance. On the other hand, the arithmetic return that focuses on average single-period performance provides an impartial estimation of future performance.

Portfolio returns (arithmetic or geometric) are usually published in an annualized form using Equation 4:

$R_{X \text { p.a. }}=\left(1+R_{X}\right)^{12}-1$

Measures of risk: The total risk of a portfolio is indicated by the standard deviation of its time-series returns. The $T$-month annualized standard deviation for the monthly returns of portfolio $X$ is computed using Equation 5:

$\sigma_{X \text { p.a. }}=\sqrt{\frac{\sum_{t=1}^{T}\left(r_{X, t}-R_{X}\right)^{2}}{T-1}} \times \sqrt{12}$ 
Where:

$r_{X, t} \quad$ is the return of portfolio $X$ in month $t$;

$R_{X} \quad$ is the $T$-month arithmetic average return of portfolio $X$; and

$T \quad$ is the number of months in the holding period.

When an asset is included as a constituent in a large well-diversified portfolio, the more relevant measure of risk is its systematic risk. Systematic risk, measured by the beta coefficient, refers to the variations of an asset's return in association with factors common to the market that cannot be diversified away. The beta coefficient of an asset $i$ is computed using Equation 6:

$\beta_{i, m}=\frac{\operatorname{Cov}\left(r_{i}, r_{m}\right)}{\sigma_{m}^{2}}$

Where:

$r_{i} \quad$ is the return of asset $i$;

$r_{m} \quad$ is the return of the market proxy;

$\operatorname{Cov}\left(r_{i} ; r_{P}\right) \quad$ is the covariance between the $r_{i}$ and $r_{m}$; and

$\sigma_{m}^{2} \quad$ is the variance of $r_{m}$.

DeFusco et al. (2004) argues that investors are particularly concerned with downside risk. This concern of investors led to the development of downside risk measures. Semi-variance, defined as the average squared deviation below the portfolio's average return, only incorporates the months in which the portfolio return falls below its historical average in the computation of portfolio risk. The semi-variance for negatively skewed portfolio returns is greater than $50 \%$ of its variance, and vice versa (Estrada, 2003). The annualized semi-deviation, defined as the positive square root of semi-variance, for portfolio $X$ over $T$-month evaluation period can be computed using Equation 7:

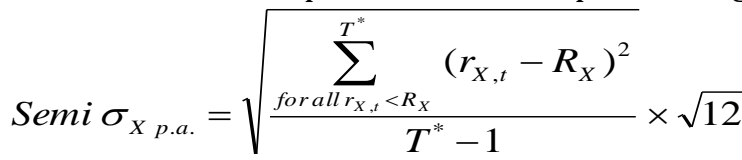

Where:

$r_{X, t} \quad$ is the return of portfolio $X$ in month $t$;

$R_{X} \quad$ is the $T$-month arithmetic average return of $X$; and

$T^{*} \quad$ is the total number of months in the $T$-month evaluation period with $r_{X, t}<R_{X}$.

Nawrocki (1999) indicates that a variant of semi-deviation, target semi-deviation that replaces the historical average returns in Equation 7 with the pre-defined target return, $R_{X}$, has become the industry standard as a measure of downside risk.

The other popular downside risk estimate, the maximum drawdown of the portfolio, measures the largest loss from peak to trough over the examination period. The maximum drawdown of the portfolio indicates the maximum possible loss investors have ever experienced over the examination period. Maximum drawdown is an important downside risk measure compared to traditional risk measures such as the beta coefficient and standard deviation as these traditional risk measures are based on the assumption that the risk level of the portfolio is stationary over the examination period. However, investors might experience sudden significant loss during crises that are quite unexpected. The maximum drawdown of portfolio $X$ over the period from period 0 to period $T$ is computed using Equation 8:

$$
M D D_{X, T}=\min _{t \in(0, T)} \frac{C R_{X}(\tau)}{\max _{t \in(0, T)} C R_{X}(t)}-1 \quad \ldots \ldots . .0 \leq t \leq T
$$

Where:

$C R_{X}(\tau)$ is the cumulative return since $t=0$ until trough $\tau$ following the period of maximum cumulative return $\max _{t \in(0, T)} C R_{X}(t)$.

\section{Risk-Adjusted Performance Measures}

Modern Portfolio Theory (MPT) pioneered by Markowitz (1952), postulates that investment performance is driven by the risk inherent in the investment, and portfolio performance should be measured as the 
compensation for the risky venture. Popular risk-adjusted performance measures discussed in this section include the coefficient of variation (CV), Sharpe ratio (SR), the Treynor measure (TM), Jensen's alpha ( $\alpha$ ), the information ratio (IR) and $\mathrm{M}$-squared $\left(\mathrm{M}^{2}\right)$.

Standard deviation-adjusted measures: The coefficient of variation (CV) measures the amount of risk borne by the investor for each percent of return earned on the asset. Thus, lower coefficient of variation is generally preferred by investors. The major disadvantage of using the coefficient of variation as a riskadjusted performance measure is that when portfolio returns are close to zero, the coefficient of variation will be meaningless as it approaches infinity. The coefficient of variation for asset $I$ is computed using Equation 9:

$$
C V_{i}=\frac{\sigma_{i}}{r_{i}}
$$

Where:

$r_{i} \quad$ is the return of asset $i$; and

$\sigma_{i} \quad$ is the standard deviation of $r_{i}$.

Unlike the coefficient of variation that measures the amount of risk borne per unit of return, most riskadjusted performance measures are formatted as reward-to-risk ratios. The Sharpe ratio is originally introduced by Sharpe (1966) as the portfolio's excess return per unit of standard deviation to measure the performance of mutual funds. The annualized Sharpe ratio for portfolio $X$ is calculated using Equation 10:

$$
S R_{X \text { p.a. }}=\frac{R_{X \text { p.a. }}-R_{f \text { p.a. }}}{\sigma_{X \text { p.a. }}}
$$

Where:

$R_{f p . a .} \quad$ is the annualized return for the risk-free asset;

$R_{X \text { p.a. }} \quad$ is the annualized return for portfolio $X$; and

$\sigma_{X \text { p.a. }} \quad$ is the annualized standard deviation for portfolio $X$.

While the Sharpe ratio measures the excess return as the difference between the return of the portfolio and the risk-free rate, the information ratio, on the other hand, measures the portfolio performance against a comparable benchmark rather than the risk-free rate. The portfolio return in excess of the return of the benchmark is known as the active return, and the variability of the active return is known as the active risk or tracking error of the portfolio (Bailey, Richards and Tierney, 2007). The active return per unit of active risk is known as the information ratio. The annualized information ratio for portfolio $X$ is computed using Equation 11:

$$
I R_{X} \text { p.a. }=\frac{R_{X \text { p.a. }}-R_{B \text { p.a. }}}{\sigma_{X-B} \text { p.a. }}
$$

Where:

$R_{B \text { p.a. }}$

$\sigma_{X-B \text { p.a }}$

is the annualised geometric return for the benchmark; and

is the annualized standard deviation for the active return of portfolio $X$ in excess of the benchmark return.

Similar to the Sharpe ratio and the information ratio, $\mathrm{M}$-squared $\left(\mathrm{M}^{2}\right)$ is a risk-adjusted performance measure that uses standard deviation as the measure of risk embedded in the portfolio. Graham and Harvey (1997) derive M-squared (later popularized by Modigliani and Modigliani, 1997) by levering or unlevering the portfolio being evaluated to achieve the same standard deviation of the market proxy. The return of the levered or unlevered portfolio can thus be compared to the return of the market proxy, on equal footing.

Figure 1, adapted and modified from Bodie, Kane and Marcus (2008: 855), illustrates M-squared of an underperforming portfolio $X$, and an outperforming portfolio $Y$. The $\mathrm{M}$-squared measure $\left(\mathrm{M}^{2}\right)$ is derived by levering or unlevering the portfolio under evaluation to arrive at the same standard deviation as the market proxy. The return of the new portfolio after the leverage adjustments (assigned with an asterisk, “*”) can then be compared to the return on the market proxy. The capital allocation line (CAL) that goes through the market proxy, namely, the capital market line (CML), is employed as the benchmark to judge the 
performance of the portfolios. Portfolios located on capital allocation line $Y$ (CAL $Y$ ) that lies above the CML have positive M-squared and are thus undervalued. Contrary to this, portfolios located on capital allocation line $X(\mathrm{CAL} X)$ that lies below the CML have negative M-squared and are thus overvalued.

To compute M-squared for the two portfolios, portfolio $X$ has to be unlevered and portfolio $Y$ has to be levered respectively to arrive at the same risk as the market $\left(\sigma_{m}\right)$. The return on the unlevered portfolio $X$ $\left(R_{X}^{*}\right)$ and the levered portfolio $Y\left(R_{Y}^{*}\right)$ can then be compared to the return of the market proxy $\left(R_{m}\right)$. Since M-squared for portfolio $X$ is negative and M-squared for portfolio $Y$ is positive, portfolio $X$ is overvalued and portfolio $Y$ is undervalued based on the M-squared measure.

\section{Figure 1: Illustration of the M-squared Measure}

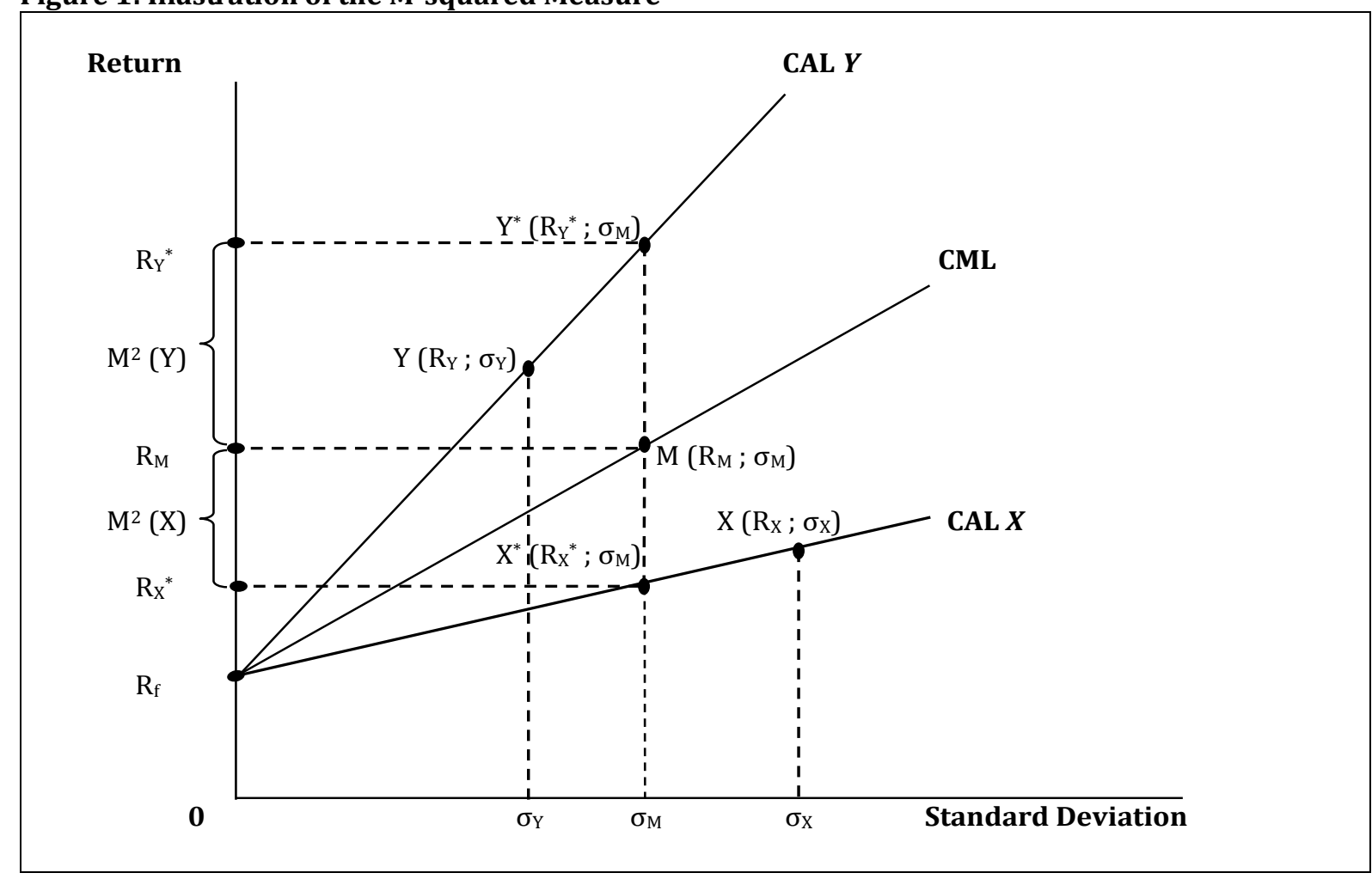

The slope of the capital allocation line (CAL) indicates the reward-to-risk ratio for the assets plotted on the CAL. The slope of CAL X indicates the reward-to-risk ratios for both portfolio $X$ and portfolio $X^{*}$ as shown in Equation 12.

$$
\frac{R_{X}-R_{f}}{\sigma_{X}}=\frac{R_{X}{ }^{*}-R_{f}}{\sigma_{M}}
$$

Where:

$R_{X} \quad$ is the return for portfolio $X$;

$R_{\mathrm{f}} \quad$ is the risk-free rate of return;

$R_{X}{ }^{*} \quad$ is the return on the leverage-adjusted portfolio $X$, which has the same standard deviation as the market proxy;

$\sigma_{X} \quad$ is the standard deviation of portfolio $X$; and

$\sigma_{M} \quad$ is the standard deviation of the market proxy.

Equation 12 can be rewritten as $\sigma_{X} \times\left(R_{X}{ }^{*}-R_{f}\right)=\sigma_{M} \times\left(R_{X}-R_{f}\right)$.

Dividing both sides by $\sigma_{X}$, the above equation evolves to:

$\left(R_{X}{ }^{*}-R_{f}\right)=\frac{\sigma_{M}}{\sigma_{X}} \times\left(R_{X}-R_{f}\right)$; and $R_{X}{ }^{*}=R_{f}+\frac{\sigma_{M}}{\sigma_{X}} \times\left(R_{X}-R_{f}\right)$. 
Defining M-squared for portfolio $X$ as $R_{X}{ }^{*}-R_{M}$, the elements of the above equation are rearranged to arrive at Equation 13:

$M^{2}(X)=R_{X}{ }^{*}-R_{M}=\left[R_{f}+\frac{\sigma_{M}}{\sigma_{X}} \times\left(R_{X}-R_{f}\right)\right]-R_{M}$

According to Bodie et al. (2008), M-squared and the Sharpe ratio are directly related. Extracting $\sigma_{M}$ from the right-hand side of Equation 13, the link between M-squared and the Sharpe ratio of portfolio $X$ can be established as follows:

$$
\begin{aligned}
& M^{2}(X)=\sigma_{M} \times\left(\frac{R_{f}}{\sigma_{M}}+\frac{R_{X}-R_{f}}{\sigma_{X}}-\frac{R_{M}}{\sigma_{M}}\right) ; \text { and } \\
& M^{2}(X)=\sigma_{M} \times\left(\left(\frac{R_{X}-R_{f}}{\sigma_{X}}\right)-\left(\frac{R_{M}-R_{f}}{\sigma_{f}}\right)\right)=\sigma_{M} \times\left(S R_{X}-S R_{M}\right)
\end{aligned}
$$

Where:

$S R_{X} \quad$ is the Sharpe ratio for fund $X$; and

$S R_{M} \quad$ is the Sharpe ratio for the market proxy.

Equation 14 states that the M-squared of portfolio $X$ is equal to the product of the volatility of the market proxy and the Sharpe ratio differential between portfolio $X$ and the market proxy. Hence, portfolios with Sharpe ratios higher than the Sharpe ratio of the market proxy are automatically assigned with a positive M-squared.

Beta coefficient-adjusted measures: The remaining two performance evaluation measures, Jensen's alpha and the Treynor measure, employ the beta coefficient rather than the standard deviation as the measure of portfolio risk. The beta coefficient, based on the capital asset pricing model (CAPM) of Sharpe (1964) and Lintner (1965), measures the sensitivity of portfolio returns to movements in the market portfolio return. The beta coefficient of portfolio $X$ is estimated by regressing the time-series excess return of the portfolio on the time-series excess return of the market proxy using Equation 15:

$r_{X, t}-r_{f, t}=\alpha_{X}+\beta_{X, M} \times\left(r_{M, t}-r_{f, t}\right)+\varepsilon_{X, t}$

Where:

$\begin{array}{ll}r_{X, t,} & \text { is the return of portfolio } X \text { in month } t ; \\ r_{f, t} & \text { is the return of the risk-free proxy in month } t ; \\ r_{X, t}-r_{f, t} & \text { is the return of portfolio } X \text { in excess of the risk-free rate in month } t ; \\ r_{M, t}-r_{f, t} & \text { is the return of the market proxy } M \text { in excess of the risk-free rate in month } t ; \\ \alpha_{X} & \text { is the intercept of the regression; } \\ \beta_{X, M} & \text { is the beta estimate for portfolio } X \text { against market proxy } M ; \\ \varepsilon_{X, t} & \text { is the residual of the regression for portfolio } X \text { in month } t .\end{array}$

Based on the beta estimate obtained from Equation 15 together with the annualized portfolio return, riskfree rate and the return on the market proxy, the annualized Jensen's alpha that measures the abnormal return of portfolio $X$ is calculated as follows:

$$
\alpha_{X \text { p.a. }}=R_{X_{\text {p.a. }}}-\left[R_{f_{\text {p.a. }}}+\beta_{X, M} \times\left(R_{M_{\text {p.a. }}}-R_{f_{\text {p.a. }}}\right)\right]
$$

Ferson and Mo (2013) suggest that performance evaluation measures based on factor models such as Jensen's alpha should be handled with care and should not evaluate after-cost fund returns with benchmark returns that are usually before-cost based.

The Treynor measure, on the other hand, is a reward-to-risk ratio that standardizes the excess return of the portfolios by their respective beta coefficients. Substituting the beta coefficient estimated in Equation 15 for the standard deviation of the annualized Sharpe ratio in Equation 10, the annualized Treynor measure for portfolio $X$ is computed in Equation 17: 


$$
T M_{X \text { p.a. }}=\frac{R_{X p . a .}-R_{f_{p . a .}}}{\beta_{X, M}}
$$

Comparison of risk-adjusted performance measures: The difference between the Sharpe ratio and the Treynor measure lies in their specific risk measure that is used to discount the excess return of the portfolio being evaluated. Due to the fact that the only relevant risk in the computation of the Treynor measure is systematic risk, the Treynor measure is only useful for evaluating portfolios that are constituents of a broader, diversified portfolio (Reilly and Brown, 2003). With regard to the comparison between the Sharpe ratio and M-squared, although both measures reach the same evaluation result, it is easier to interpret M-squared than the Sharpe ratio, as M-squared provides a direct comparison between the leverage-adjusted portfolio and the market portfolio. The information ratio, on the other hand, is useful for evaluating hedge funds that have an objective to achieve absolute returns as it measures the reward-torisk ratio of a portfolio against the performance of an explicit benchmark (Gupta, Prajogi, and Stubbs, 1999). The other relative performance measure, Jensen's alpha, implicitly identifies the risk-adjusted return estimated by the CAPM as the benchmark for the portfolio being evaluated.

Which measure to use? Implications for modern practices and hedge funds: The growing number of fund performance indicators can cause unnecessary confusion in the evaluation process as there could be non-convergence in the ranking from different measures. Problems also arise when evaluating the performance of hedge funds with returns that are not normally distributed. Kao (2002) suggests that hedge funds that employ derivatives in their investment strategies present different return distributions compared to long-only portfolios. The use of derivatives might result in a skewed distribution of returns with abnormal kurtosis in the distribution (Kat, 2003). Thus, the traditional performance evaluation measures discussed above might not be able to accommodate fund returns that are not normally distributed (Huang, 2012). Based on the above argument, Eling and Schuhmacher (2007) investigate the consistency of various performance evaluation measures in ranking 2,763 hedge funds over the period from 1985 to 2004. The performance measures examined in their study include the traditional Sharpe ratio, the Treynor measure and Jensen's alpha discussed in this paper, as well as the Omega ratio, Sortino ratio, Kappa 3, the upside potential ratio, the Calmar ratio, the Sterling ratio, the Burke ratio, the excess return on value-at-risk, the conditional Sharpe ratio, and the modified Sharpe ratio. The results of their tests show that the rank correlation coefficients between the performance measures are $90 \%$ and above.

Eling (2008) conducts further tests on 38,954 funds that cover a large variety of asset classes, including stocks, bonds, real estates, commodities and hedge funds over the period from 1996 to 2005. Tests results indicate that the choice of any measure does not have significant influence on the ranking of funds with different return distributions. Eling (2008) further argues that the Sharpe ratio, as the best understood measure by investors, is consistent with the expected utility maximization function and should be adapted to measure returns of most modern investment vehicles, including hedge funds. Razafitombo (2010) attempts to establish the relative appropriateness of a vast variety of performance measures, including beta, bear and bull betas, absolute performance, relative performance, maximum drawdown, number of negative and positive periods, standard deviation, tracking error, information ratio, Sharpe ratio, Treynor ratio, Jensen's alpha and Sortino ratio over the period from 2000 to 2006. Test results show inconsistencies between the rankings of different measures over time. Moreover, inconsistencies are also present in the same measure over different periods. Razafitombo (2010) concludes that various measures should be employed in a multi-criteria approach to evaluate fund performance in order to achieve unbiased results.

\section{Performance Attribution}

Performance attribution refers to the procedure that determines the relative importance of the various sources from which a portfolio generates its returns. Sharpe (1992) proposes the use of a return-based multifactor model to analyze the return attribution of actively-managed portfolios. The implementation of this approach requires the construction of factor-mimicking portfolios that symbolize the major asset classes and investment styles as shown in Equation 18:

$$
R_{i, t}=\sum_{k=1}^{N} b_{i, k} \times R_{k, t}+\varepsilon_{i, t}
$$


Where:

$R_{i, t} \quad$ is the return of portfolio $i$ in month $t$;

$R_{k, t} \quad$ is the return on the $k$ th asset class/style index in month $t$;

$b_{i, k} \quad$ is the exposure of portfolio $i$ 's return to movements in $R_{k, t}$;

$\varepsilon_{\mathrm{i}, \mathrm{t}} \quad$ is the part of the return that cannot be explained by the major asset classes/styles (i.e. the selection return); and

$\sum_{k=1}^{N} b_{i, k} \times R_{k, t} \quad$ is the benchmark return that tracks the returns of asset classes/styles.

Equation 18 distinguishes a portfolio's return from its selection return that is unrelated to the portfolio's underlying investment styles or asset classes. The benchmark return decomposes a portfolio's return into the component returns generated from various asset classes/style indexes. When the sum of the coefficients is constrained to be $100 \%$, the coefficient estimated represents the weight or proportion of the portfolio's investment allocated to the respective asset class/style index. The selection return of the fund arises from the portfolio manager's discretion when allocating stocks differently from the designated asset class/style indexes proxied by the benchmark return.

Performance attribution of long-only mutual funds: Sharpe (1992) analyzes the performance of mutual funds in the U.S. over the period from 1985 through 1989. The 12 asset classes and style indexes employed by Sharpe (1992) include the 90-day U.S. Treasury bill, the intermediate-term government bond index, the long-term government bond index, the corporate bond index, the mortgage-backed security index, the large-cap value stock index, the large-cap growth stock index, the medium-cap stock index, the small-cap stock index, the non-U.S. government bond index, the European stock index and the Japanese stock index. The results indicate that the return-based multifactor model effectively explains the performance of U.S. mutual funds with out-of-sample $R$-squared of above $80 \%$. The selection returns of the funds under analysis are statistically insignificant over the out-of-sample period. The return-based multifactor model of Sharpe (1992) is also adapted by Ibbotson and Kaplan (2000) and Vardharaj and Fabozzi (2007) to analyse the return attribution of U.S. mutual funds over the period from 1988 to 1998 and 1995 to 2004 respectively. Both studies find that the performance of U.S. mutual funds is dominated by their benchmark returns with insignificant selection returns.

When the return-based multifactor model of Sharpe (1992) is tested on the South African unit trust industry, Yu (2008) find that the return attributions of South African unit trusts are primarily explained by the resource index, the industrial index, the financial index and the value, size and momentum style indexes. Hsieh and Hodnett (2011) use the Morgan Stanley Capital International Composite Index as the market proxy and three global style proxies, namely the momentum index, the value index and the size index to replicate the performance of global equity funds over the period from 2002 to 2008 . It is found that the combination of the market proxy and the style proxies successfully explain the return attribution of internationally-domiciled global equity funds.

Performance attribution of hedge funds: The traditional asset classes and style indexes in the returnbased multifactor models are insufficient in explaining the performance of hedge funds that engage in short sales, leverage and derivatives in their trading activities in the study conducted by Fung and Hsieh (1998) over the period from 1991 to 1995. Fung and Hsieh (1998) argue that factor analysis has an ability to extract style rotation or hedge fund styles that are not available from common style indexes. Fung and Hsieh (1998) extend the multifactor model of Sharpe (1992) by updating the identities of the factors in the model to incorporate the dynamics of the hedge fund industry. The results indicate that the updated model successfully explains the performance attribution of U.S. hedge funds over the examination period. An alternative solution provided by Baghai-Wadji and Klocker (2007) is to use factors extracted from the cluster analysis based on a self-organizing map (SOM) algorithm in a neural network that groups hedge funds into homogenous style-consistent categories. This approach is found to significantly explain the return attribution of U.S. hedge funds over the period from 1992 to 2004.

Market timing and selectivity: Philippas (2002) points out that traditional performance evaluation measures fail to distinguish the ability of the portfolio managers in terms of their market timing skill and the security selection ability. The performance attribution models developed by Treynor and Mazuy (1966) and Henriksson and Merton (1981) could be adapted to address this issue. Both of these models introduce 
an additional factor to the CAPM to capture the market timing ability of the portfolio manager. According to Treynor and Mazuy (1966), the excess return on portfolio $X$ is a nonlinear function of the market returns as shown in Equation 19:

$$
r_{X, t}-r_{f, t}=\alpha_{X}+\beta_{X, M} \times\left(r_{M, t}-r_{f, t}\right)+c_{X, M} \times\left(r_{M, t}-r_{f, t}\right)^{2}+\varepsilon_{X, t}
$$

On the other hand, the Henriksson and Merton (1981) attach a dummy variable to the variations in the market risk premium as shown in Equation 20:

$$
r_{X, t}-r_{f, t}=\alpha_{X}+\beta_{X, M} \times\left(r_{M, t}-r_{f, t}\right)+c_{X, M} \times\left(r_{M, t}-r_{f, t}\right) \times D_{t}+\varepsilon_{X, t}
$$

Where $D_{t}=1$ when $r_{M, t}-r_{f, t}>0$; and $D_{t}=0$ when $r_{M, t}-r_{f, t} \leq 0$.

The market timing ability of the portfolio manager is evaluated by the statistical significance of the coefficient $c_{X, M}$ while the security selection ability of the portfolio manager is evaluated by the statistical significance of $\alpha_{X}$ in Equation 19 and Equation 20.

\section{Conclusion}

This paper compares and contrasts the pros and cons of the primary performance evaluation measures. With regard to measures of portfolio returns, geometric return should be used for evaluation purposes to avoid ambiguity caused by the arithmetic average of historical gains and losses. When evaluating the level of risk inherent in the portfolio, downside risk measures such as semi-variance and maximum drawdown should be examined during turbulent times. The maximum drawdown of a portfolio has become an important downside risk measure as it relaxes the assumption that the portfolio risk is constant over the evaluation period. When risk is incorporated in the evaluation of a portfolio's performance, the M-squared is easier understood by investors compared to the Sharpe ratio, as it provides direct comparison between the return of the portfolio and the return of the market proxy. The Treynor measure is only suitable for evaluating portfolios that are constituents of a broader, more diversified portfolio. Jensen's alpha and the information ratio are suitable for evaluating the performance of hedge funds as they provide direct comparison between the risk-adjusted return of the portfolio and its benchmark. With regard to the consistency of ranking performance measures, the test results of Razafitombo (2010) are in direct contradiction to the findings of Eling and Schuhmacher (2007) and Eling (2008). While Razafitombo (2010) discovers ranking inconsistencies between measures over different time periods, Eling and Schuhmacher (2007) and Eling (2008) find evidence of ranking consistencies between performance measures for evaluations conducted on a variety of funds and hedge funds with different return distributions. This paper supports the view of Razafitombo (2010) in adopting a multi-criteria approach to avoid potentially biased results.

The three major sources of portfolio performance include the asset allocation ability, the security selection ability and the market timing ability of the portfolio manager. Using the return-based multifactor model of Sharpe (1992), the portfolio returns are dissected into asset allocation return and security selection return. The Treynor and Mazuy (1966) model and the Henriksson and Merton (1981) model, on the other hand, distinguish the market timing ability from the security selection ability of the portfolio manager. The Sharpe (1992) multiple regression is found to explain the return attributions of most long-only mutual funds across regions and time periods. However, empirical evidence has shown that additional factors need to be included to capture the unique risk orientations of hedge funds that engage in short-selling, leverage and derivatives.

\section{References}

Baghai-Wadji, R. \& Klocker, S. (2007). Performance and style shifts in the hedge fund industry. London Business School, Working Paper.

Bailey, J. V., Richards, T. M. \& Tierney, D. E. (2007). Managing investment portfolios: a dynamic process. 3rd Edition, CFA Institute.

Bodie, Z., Kane, A. \& Marcus, A. J. (2008). Investments. 7th Edition, McGraw Hill.

Damato, K. (2001). Doing the math: tech Investors' road to recovery is long. Wall Street Journal, 18, C1C19. 
DeFusco, R. A., Mcleavey, D. W., Pinto, J. E. \& Runkle, D. E. (2004). Quantitative methods for investment analysis. 2nd Edition, CFA Institute.

Eling, M. \& Schuhmacher, F. (2007). Does the choice of performance measure influence the evaluation of hedge funds? Journal of Banking \& Finance, 31, 2632-2647.

Eling, M. (2008). Does the measure matter in the mutual fund industry? Financial Analysts Journal, 64(3), $1-13$.

Estrada, J. (2003). Mean-semivariance behavior: a note. Finance Letters, 1(1), 9-14.

Ferson, W. \& Mo, H. (2013). Performance measurement with market and volatility timing and selectivity. Marshall School of Business, University of Southern California, Working Paper.

Fung, W. \& Hsieh, D. A. (1998). Performance attribution and style analysis: from mutual funds to hedge funds. Paradigm Financial Products, Principal Publisher.

Graham, J. R. \& Harvey, C. R. (1997). Grading the performance of market-timing newsletters. Financial Analysts Journal, 53(6), 54-66.

Gupta, F., Prajogi, R. \& Stubbs, E. (1999). The information ratio and performance. Journal of Portfolio Management, 26, 1-8.

Henriksson, R. \& Merton, D. L. (1981). On market timing and investment performance. Journal of Business, $57(4), 513-534$.

Hsieh, H. \& Hodnett, K. E. (2011). Do managers of global equity funds outperform their respective style benchmarks? An Empirical Investigation. International Business and Economic Research Journal, $10(12), 1-10$.

Huang, F. (2012). An investigation of the risk-adjusted performance of Canadian REIT mutual funds and the market timing skills of fund managers. Concordia University, Unpublished Master of Science in Administration thesis.

Ibbotson, R. D. \& Kaplan, P. (2000). Does asset allocation policy explain 40, 90, or 100 percent of performance? Financial Analysts Journal, 56(1), 26-33.

Jensen, M. C. (1968). The performance of mutual funds in the period 1945-1964. Journal of Finance, 23, $389-416$.

Kao, D. (2002). Battle for alphas: hedge funds versus long-only portfolios. Financial Analysts Journal, 58(2), 16-36.

Kat, H. M. (2003). 10 things that investors should know about hedge funds. Journal of Wealth Management, 5, 72-81.

Kruger, R. \& van Rensburg, P. (2008). Evaluating and constructing equity benchmarks in the South African portfolio management context. Investment Analysts Journal, 67(1), 1-13.

Lintner, J. (1965). The valuation of risky assets and the selection of risky investments in stock portfolios and capital budgets. Review of Economics and Statistics, 47(1), 13-37.

Markowitz, H. M. (1952). Portfolio Selection. Journal of Finance, 1 7(1), 77-91.

Modigliani, F. \& Modigliani, L. (1997). Risk-adjusted performance. Journal of Portfolio Management, 23(2), 45-54.

Nawrocki, D. N. (1999). A brief history of downside risk measures. Journal of Investing, 8(3), 9-25.

Philippas, N. (2002). Market timing and selectivity: an empirical investigation into the features of Greek mutual fund managers. The Journal of Applied Business Research, 18(3), 97-108.

Razafitombo, H. (2010). A statistical analysis of mutual fund performance measures: the relevance of IRs, Betas, and Sharpe ratios. Journal of Index Investing, 1(2), 89-106.

Reilly, F. K. \& Brown, K. C. (2003). Investment analysis and portfolio management. 7th Edition, Thomson Learning.

Sharpe, W. F. (1964). Capital asset prices: a theory of market equilibrium under conditions of risk. Journal of Finance, 19(3), 425-442.

Sharpe, W. F. (1966). Mutual fund performance. Journal of Business, 39(1), 119-138.

Sharpe, W. F. (1992). Asset allocation: management style and performance measurement. Journal of Portfolio Management, 18, 7-19.

Treynor, J. L. \& Mazuy, J. (1966). Can Mutual Funds Outguess the Market? Harvard Business Review, 44(4), 131-136.

Yu, X. (2008). Style Indices and active portfolio construction on the JSE. University of Cape Town, Working Paper.

Vardharaj, R. \& Fabozzi, F. J. (2007). Sector, style, and region: explaining stock allocation performance. Financial Analysts Journal, 63(3), 59-70. 